\title{
1995: OS DIREITOS HUMANOS EM "SURSIS"
}

\author{
J.A. LINDGREN ALVES
}

Um ano e meio após a confirmação consensual de sua universalidade pela Conferência de Viena de 1993, os direitos humanos parecem ter entrado em quarentena na esfera internacional. Lamentável em qualquer circunstância, essa aparente "suspensão de aplicabilidade" se afigura ainda mais absurda neste ano do Qüinquagésimo Aniversário das Nações Unidas, que, coincidentemente, inaugura a "Década Internacional da Educação em Direitos Humanos". 1

Contrariamente ao espírito universalista que terminou por prevalecer na Declaração de Viena, e em contradição com o que eles próprios nela haviam acordado, alguns governos retomaram a prática de objetar a legitimidade da preocupação internacional com a situação dos direitos humanos das respectivas populações, invocando novamente a ultrapassada versão da "ocidentalidade" de tais direitos, e exumando o conceito hobbesiano de soberania. Pior ainda, na recente Cúpula sobre o Desenvolvimento Social de Copenhague, alguns desses mesmos governos, associados naquela instância a vários outros, procuraram a todo custo, nas negociações sobre o documento a ser adotado, fazer retroceder os avanços conceituais em matéria de direitos aprovados seis meses antes no Programa da Ação do Cairo, da Conferência Internacional sobre População e Desenvolvimento.

$\mathrm{Se}$, por um lado, ainda tem sido possível ao conjunto majoritário de países, nos foros multilaterais, sobrepor-se grosso modo a essas iniciativas "revisionistas", evitando retrocessos nas conquistas conceituais de documentos internacionais normativos, o cenário internacional contemporâneo não parece de molde a oferecer fortes contrapesos aos movimentos retrógrados.

1 Proclamada pela Resolução 49/184 da Assembléia Geral, em 23 de dezembro de 1994. 
É verdade evidente que o triunfalismo liberal-capitalista da primeira fase do período pós-Guerra Fria não passou de fogo-fátuo. É também hoje amplamente reconhecido, à luz das dificuldades e problemas atuais dos próprios países ocidentais desenvolvidos, que o fim da Guerra Fria não teve propriamente "vencedores", nem propiciou a emergência de um novo sistema internacional mais estável. Fala-se, inclusive, e não sem fundamento, que as características da realidade atual mais a aproximam de uma nova Idade Média do que de uma Nova Ordem Internacional.

Com efeito, em vista do crescimento avassalador dos fundamentalismos de todos os tipos - religiosos, nacionalistas, étnicos, "raciais", xenofóbicos, econômicos, e comportamentais - epitomáveis, respectivamente, nos casos mais recentes da Argélia, da Chechênia, de Ruanda, das manifestações anti-semitas na Europa, das agressões aos turcos na Alemanha, do culto exagerado do mercado, e da obsessão pelo "politicamente correto" -, não há dúvida de que a vertente integrista desta "pós-modernidade" tende a balizar-se pelo sepultamento da Razão iluminista. Em tal contexto, a postulação da tolerância e dos elementos humanos universais existentes em qualquer situação particular apresenta-se problemática.

Ainda assim, a afirmação do funcionalismo e das complementaridades solidárias nas relações internacionais e no encaminhamento dos "temas globais" pode e deve ser buscada. E é a isso que se dedica, malgrado todos os percalços da História contemporânea, a agenda social e humanitária das Nações Unidas, respaldada pela embriônica "sociedade civil globalizada" das ONGs.

\section{A 51ª SESSÃo}

Tendo por pano de fundo mais de trinta conflitos sangrentos de caráter não-internacional, a $51^{2}$ Sessão da Comissão dos Direitos Humanos das Nações Unidas, em fevereiro/março de 1995, revelou-se, mais do que anteriormente, uma moldura pouco apropriada à consideração efetiva de meios e modos para fazer progredir a causa dos direitos humanos no mundo atual, particularmente em situações nacionais conflagradas. Destas, as evidentemente mais graves, como as da Bósnia, da Chechênia e de Ruanda, extràpolam de tal maneira as possibilidades de eficácia dos mecanismos de que dispõe a Comissão, que a designação de relatores especiais ou o envio de missões de inspeção - suas "armas" habituais - adquire feições irrisórias. A proliferação de situações de conflito armado, por sua vez, dificulta a consideração das violações mais "rotineiras", nãodecorrentes de convulsões sociais ou disputas bélicas. 
Pela própria magnitude de seus números, o caso de Ruanda é exemplo eloqüente da inadequação do sistema das Nações Unidas - e não apenas da Comissão dos Direitos Humanos - para lidar com carnificinas de grandes proporções. O caso da Bósnia; que se eterniza, evidencia muito mais a falta de determinação da comunidade internacional para resolvê-lo.

A propósito de Ruanda, como observa Bernard-Henri Lévy: "Há genocídios que fizeram mais vítimas. Nenhum havia feito tantas (um milhão) em tão pouco tempo (seis semanas)... Ruanda não é Auschwitz. Nem o Cambódia. Mas tem sua própria performance, seu recorde: o recorde mundial do genocídio por hora".2

Se a cifra de um milhão mencionada pelo pensador francês for exagerada, não o será muito. Entre fins de abril e fins de maio de 1994, o número de mortos ruandeses noticiado nas agência internacionais aumentou de 100 mil para meio milhão. Levando-se em conta que a Rádio das Mil Colinas, principal meio de instigação aos massacres de tutsis, manteve-se no ar até meados de julho; que a epidemia de cólera matou, somente nas duas primeiras semanas do surto, 50 mil pessoas no campo de refugiados de Goma, no Zaire; que a "Operação Turquesa" da França somente foi autorizada pelo Conselho de Segurança em 22 de junho com mandato estritamente humanitário - em substituição à inoperante força de paz multinacional, antes retirada; que a instalação da Frente Patriótica de Ruanda no Governo de Kigali ainda tardou; não seria de estranhar que o balanço total do morticínio entre 6 de abril - data da derrubada do avião em que viajavam os Presidentes de Ruanda e do Burundi - e o final de julho exceda a estimativa conservadora dos 500 mil e se aproxime de um milhão: um sexto da população total do país. ${ }^{3}$

Um ano depois da irrupção da violência, as cifras provenientes da Ruanda continuam a impressionar: 30 mil acusados de genocídio para serem julgados em Kigali pelos escassos juízes ruandeses; um indivíduo hutu que confessa ter matado 900 pessoas; uma criança de 7 anos indiciada como genocida; um adolescente de 17 inculpado pela morte de 12 pessoas. ${ }^{4}$ Mais ainda: do morticínio de 22 de abril de 1995, no campo de refugiados de Kibeho, desta feita já perpetrado por tropas tutsis do novo governo, o número de vítimas oscila entre 8.000 , segundo as primeiras estimativas divulgadas, 2.000 , de acordo com o comandante da missão de

2 Lévy, Bernard Henri. La pureté dangereuse. Paris, Grasset, 1994, p. 54. Minha tradução.

3 Destexhe, Alain. Rwanda - Essai sur le génocide. Bruxelas, Ed. Complexe, 1994.

4 Despachos de agências internacionais publicados no Jornal do Brasil, Folha de São Paulo e O Estado de São Paulo em 7 abr. 1995. 
paz das Nações Unidas (às quais se acrescentariam 600 feridos), e 300, conforme o Presidente Pasteur Bizimungu. 5

É verdade que o sistema existente de proteção internacional aos direitos humanos inclui, desde 1948, a Convenção contra o Genocídio primeiro instrumento jurídico adotado pela ONU na esfera desses direitos. É verdade, também, que o Conselho de Segurança decidiu, em novembro de $1994,{ }^{6}$ estabelecer um tribunal internacional para julgar os responsáveis pela incitação ao genocídio em Ruanda, tendo por precedente o tribunal semelhante criado para a ex-Iugoslávia. As investigações em Ruanda já teriam, inclusive, permitido ao tribunal respectivo, sediado em Arusha, na Tanzânia, identificar 400 ideólogos do massacre. ${ }^{7}$ A Comissão dos Direitos Humanos, contudo, não tendo meios para promover a aplicação da Convenção contra o Genocídio, nem para acionar um tribunal criado por outro foro com base legal muito além de sua competência, não pode fazer mais do que já tem feito: designar e manter um relator especial para monitorar a situação do país. A designação foi até bastante célere, pois se deu em sessão especial da Comissão convocada em maio de 94, antes que o Conselho de Segurança se decidisse sobre a matéria, quando a crise começava a apresentar contornos extraordinários.

O relator especial para Ruanda, René Degni-Ségui, tem desempenhado importante e corajoso trabalho de esclarecimento sobre a fragilidade da situação atual, a requerer atuação mais eficaz da comunidade internacional para obstar novos surtos de violência étnica - de que foi triste exemplo o massacre de hutus no campo de Kibeho em 22 de abril de 1995. E o Alto Comissário das Nações Unidas para os Direitos Humanos, com escassos recursos, mas com capacidade de iniciativa ex officio, também tem feito o possível para auxiliar a região, através do estabelecimento em Ruanda e no Burundi de escritórios de representação permanentes, de natureza preventiva, com funções educativas e de supervisão, integrados por peritos e funcionários do Centro para os Direitos Humanos da ONU. Todas são, obviamente, iniciativas limitadas face à gravidade da situação, cujos problemas ameaçam alastrar-se aos países vizinhos. É particularmente delicado o caso do Burundi, de população também composta por hutus e tutsis. E por essa razão a Comissão decidiu, na última sessão, estabelecer um relator especial para aquele país, tendo sido convidado para o cargo o brasileiro Paulo Sérgio Pinheiro.

5 "Presidente culpa hutus por mortes em Ruanda", Jornal do Brasil, 22 abr. 1995.

${ }^{6}$ Resolução 955 (1994), adotada em 8 de novembro de 1994.

${ }^{7}$ Lapouge, Gilles. "Comunidade intemacional deveria criar Corte permanente". O Estado de São Paulo, 7 abr. 1995. 
Se o caso de Ruanda ilustra, a título meramente exemplificativo, a inadequação de meios da comunidade internacional para lidar com um dos tipos de fenômenos da "pós-modernidade" — que é ultramoderno apenas porque visível nas telas de televisão -, o caso da Argélia evidencia outro tipo de dificuldade atual: o fanatismo religioso e as formas legítimas de seu controle.

Em uma única semana do início de março último, o governo argelino registrou importante "vitória" contra a Frente Islâmica de Salvação - FIS, eliminando, em três ações militares, 1200 fundamentalistas do Grupo Islâmico Armado - GIA. O FIS, com seus fous de Dieu, por sua vez, na "guerra santa" de eliminação da impureza, além de anatematizar o Ocidente, de condenar à morte os estrangeiros, de promover o extermínio de jornalistas e intelectuais "ocidentalizados", de degolar mulheres pelo "pecado" de não ocultarem os cabelos, de incendiar escolas públicas laicas (por não ensinarem o Corão), parece ter dado início a ações terroristas de escopo internacional, ao seqüestrar em dezembro de 1994 um Airbus da Air France.

No Sudão o governo integrista mantém a recusa em acolher o relator especial da Comissão dos Direitos Humanos, o húngaro Gaspar Bíró, porque este se obstina em apontar a inadequação do direito penal vigente no país às normas e padrões dos instrumentos internacionais de direitos humanos. No Iraque, de governo supostamente laico, a shari'a é reinstituída como lei estatal, com amputações transmitidas pela televisão. Bangladesh bane Taslima Nasrin por ofender as tradições islâmicas nacionais. No Paquistão, motins populares explodem em repúdio à comutação da pena de morte contra cristãos que haviam pixado uma mesquita. A fatwa xiita contra Salman Rushdie permanece em vigor. E a França, em defesa do liberalismo, proíbe o uso de véu por estudantes muçulmanas.

Quando o integrismo é doutrina de governo, a Comissão dos Direitos Humanos não tem tido maiores problemas em fazer passar resoluções. Afinal o "alvo" visado é essencialmente o próprio governo, que, em teoria, precisa seguir as normas e padrões internacionais de comportamento, e pode ser pressionado. Ainda que os respectivos relatores não tenham podido entrar nos países fundamentalistas monitorados (todos agora tendem a sê-lo), a renovação anual de seus mandatos é vigorosamente objetada pelos governos em questão - o que demonstra não serem anódinas as resoluções da Comissão. Quando o integrismo é, porém, de oposição, quase sempre na forma de movimentos ilegais, seus códigos de conduta são exclusivos, o que os assemelha às máfias do crime, impérvias às pressões morais externas, por mais antinômicas que sejam as respectivas motivações. Torna-se, assim, inviável qualquer ação da Comissão sobre 
tais movimentos, assim como se afigura problemática a adoção de medidas sobre os eventuais excessos da repressão. Daí a inexistência até hoje de relator especial para a Argélia, em contraste com os relatores para o Irã e o Sudão, estabelecidos há anos.

Diante do quadro oferecido pela realidade concreta, não causa estranheza o fato de a $51^{2}$ Sessão da Comissão dos Direitos Humanos ter produzido parcas novidades. Das poucas dignas de nota, além da designação de um relator especial para o Burundi, e de uma declaração sobre a Chechênia, previamente negociada entre a União Européia, a Rússia e os Estados islâmicos, lida pelo presidente da sessão, houve a apresentação dos primeiros relatórios dos novos relatores temáticos sobre as formas contemporâneas de racismo e sobre a violência contra a mulher.

Uma nova figura de relator temático, de adequação duvidosa à competência daquele foro, também foi decidida, por insistência do Grupo africano, para monitorar "os efeitos adversos para os direitos humanos do despejo ilícito de lixo tóxico". Constituíram-se, ainda, dois novos grupos de trabalho normativos: para examinar projeto de declaração sobre os direitos dos indígenas emanado da Subcomissão de Prevenção da Discriminação e Proteção das Minorias (composta por peritos, a título individual), e para elaborar um projeto de protocolo opcional à Convenção sobre os Direitos da Criança dedicado às questões da venda de crianças e da prostituição e pornografia infantis.

Foram, por outro lado, renovados os mandatos de relatores e grupos de trabalho, temáticos e para situações específicas, constituídos em sessões anteriores, evitando-se, assim, pelo menos, que o sistema existente de proteção internacional aos direitos humanos sofresse retrocessos.

São atualmente monitorados por relatores ou peritos da Comissão, em tratamento não-confidencial, os seguintes países e territórios: Irã, Iraque, Afeganistão, Mianmar, Cuba, Guatemala, Sudão, Guiné Equatorial, Ruanda, Burundi, Zaire, a ilha de Bougainville (na Papua-Nova Guiné), as Repúblicas da ex-Iugoslávia, os territórios árabes ocupados por Israel, inclusive a Palestina. Deixaram de ser objeto de supervisão a África do Sul e El Salvador. Permanecem em suas funções os relatores e grupos de trabalho temáticos sobre os desaparecimentos forçados, a tortura, as execuções sumárias, a liberdade de expressão, a independência e imparcialidade do judiciário, a intolerância religiosa, o uso de mercenários, a venda de crianças e a prostituição e a pornografia infantis.

Embora represente forte decepção, a retomada por alguns governos, na Comissão dos Direitos Humanos, dos velhos argumentos da soberania e das autenticidades particulares, em contraposição à alegada "ocidentalidade" dos direitos humanos, teoricamente superados em 1993 
pela Declaração de Viena, não chega a surpreender. Que tal argumentação voltasse a ser utilizada, em época de tantos integrismos, por países afroasiáticos de tradição muçulmana era, de certa forma, previsível. Que a mesma argumentação voltasse a ser agora utilizada pela China - que já o fizera na Conferência Mundial de Direitos Humanos, mas não se recusara a aceitar a Declaração - é mais inquietante. É fato que a China o fez, em Genebra, em atitude de autodefesa, ao ver-se pressionada por projeto de resolução ocidental, no seu entender motivado apenas por objetivos políticos. Ainda assim, a utilização desses argumentos por país de tal peso específico, e que sediará em setembro próximo a IV Conferência Mundial sobre a Mulher, é especialmente preocupante. A fortiori se a China mantiver as posições que adotou em Genebra de solidariedade com os governos islâmicos integristas.

\section{OS RISCOS DE COPENHAGUE}

A Cúpula Mundial realizada em Copenhague de 6 a 12 de março de 1995, diferentemente das demais conferências da agenda social da ONU na década de 90 - a Rio-92 sobre o meio ambiente e o desenvolvimento sustentável, a Conferência de Viena de 1993 sobre direitos humanos, a Conferência do Cairo de 1994 sobre população e desenvolvimento e as futuras conferências de Pequim sobre a mulher (setembro de 95) e de Istambul sobre os assentamentos humanos (junho de 96) - foi a primeira havida sobre o tema do desenvolvimento social. Independentemente dos possíveis méritos dos documentos por ela aprovados, sua realização já teria ipso facto a inquestionável virtude de trazer, pela primeira vez, o desenvolvimento social, e tudo o que ele representa para os direitos humanos, ao nível dos "temas globais", na primeira linha das atenções internacionais.

Se, sob certos aspectos, e para as aspirações mais otimistas, a Cúpula pode ter sido frustrante, seus documentos finais - a Declaração, composta por 10 compromissos assumidos pelos Chefes de Estado e de Governo, ou seus representantes, de 185 países, e o Programa de Ação - fazem importantes contribuições ao tratamento nacional e internacional desse megatema, a que se subordinam, direta ou indiretamente, todos os demais.

De maneira extremamente simplificada, podem-se sumariar as conquistas dos documentos finais de Copenhague nos próprios compromissos da Declaração, resumíveis nas seguintes promessas coletivas dos governantes: 
1 - de criar um ambiente econômico, político, social, cultural e jurídico que permita o desenvolvimento social das pessoas;

2 - de erradicar a pobreza no mundo, por meio de ação nacional enérgica - com enfoque multidimensional e integrado, em cooperação com todos os membros da sociedade civil - e da cooperação internacional, como um imperativo ético, social, político e econômico da humanidade;

3 - de promover o pleno emprego e de capacitar os homens e as mulheres a conseguirem meios de vida seguros e sustentáveis;

4 - de promover a integração social fomentando sociedades estáveis, seguras e justas, baseadas em todos os direitos humanos;

5 - de promover o pleno respeito à dignidade humana e de alcançar a igualdade e a eqüidade entre homens e mulheres $\mathrm{e}$ de reconhecer e aumentar a participação e as funções de liderança da mulher na vida política, civil, econômica, social e cultural e no desenvolvimento;

6 - de promover e alcançar os objetivos de acesso universal e eqüitativo a uma educação de qualidade e ao nível mais alto possível de saúde física e mental, de acesso de todas as pessoas à assistência básica de saúde, procurando especialmente retificar desigualdades sociais sem distinções de raça, origem nacional, sexo, idade ou deficiência; de promoção das culturas comuns e particulares; de preservação das bases do desenvolvimento sustentável centrado nas pessoas;

7 - de acelerar o desenvolvimento econômico, social e humano da África e dos países de menor desenvolvimento ("LDCs");

8 - de assegurar que os programas de ajuste estrutural incluam objetivos de desenvolvimento e integração sociais;

9 - de aumentar substancialmente ou utilizar com maior eficácia os recursos destinados ao desenvolvimento social;

10 - de melhorar e fortalecer o quadro da cooperação internacional, regional e subregional para o desenvolvimento social, em espírito de parceria, através das Nações Unidas e outras instituições multilaterais. ${ }^{8}$

8 Documento das Nações Unidas A/CONF.166/L.3/Add.1. 
Cada um desses objetivos acima resumidos é respaldado por capítulo respectivo do Programa de Ação, em que se descreve a forma pela qual deve ser implementado.

O simples enunciado dos compromissos evidencia a importância para os direitos humanos da Cúpula de Copenhague, inegavelmente centrada na pessoa humana e nas noções de igualdade e eqüidade, a exemplo da Conferência do Cairo sobre População e Desenvolvimento. Mais concretamente para os direitos humanos a Declaração e o Programa de Ação de Copenhague apresentam incentivos concretos ao estimularem, por exemplo, "a ratificação e a plena aplicação dos instrumentos pertinentes ... como o Pacto Internacional de Direitos Econômicos, Sociais e Culturais e o Pacto Internacional de Direitos Civis e Políticos" (parágrafo 28, f); "a observância dos convênios pertinentes da Organização Internacional do Trabalho" para "proteger e fomentar o respeito aos direitos básicos dos trabalhadores, aí incluídos a proibição do trabalho forçado e do trabalho infantil, a liberdade de associação e o direito de organização e negociação coletiva e a não-discriminação no emprego" (compromisso 3, i, e parágrafo 54, b, do Programa de Ação); a proteção "de todos os direitos humanos e liberdades fundamentais, que são universais, indivisíveis, interdependentes e interrelacionados, inclusive o direito ao desenvolvimento...", o "estabelecimento de mecanismos e recursos eficazes para assegurar seu cumprimento..." e a "criação e fortalecimento de instituições nacionais responsáveis por sua aplicação e vigilância" (parágrafo 15, b); a realização do direito ao desenvolvimento "mediante o fortalecimento da democracia, o desenvolvimento e o respeito aos direitos humanos e liberdades fundamentais..."(parágrafo $15, \mathrm{~d}) .{ }^{9}$

A universalidade dos direitos humanos, consensualmente consagrada na Declaração de Viena de 1993, é, portanto, mais uma vez reiterada nos documentos de Copenhague, assim como o são a interrelação entre democracia, desenvolvimento e direitos humanos, o direito ao desenvolvimento em suas vertentes individual e coletiva, e todos os conceitos basilares das grandes conferências mundiais já realizadas na década de 90 , inclusive a abordagem das questões de gênero em todas as áreas discutidas $\mathrm{e}$ as referências à saúde reprodutiva e aos direitos a ela concernentes, entronizados na Conferência do Cairo.

Vistos assim, a posteriori, os documentos da Cúpula de Copenhague aparecem extremamente positivos para os direitos humanos. As frustrações verbalizadas sobre a Cúpula não dizem respeito a essa esfera,

9 Documentos das Nações Unidas A/CONF.166/L.3/Add.2 a 7. 
mas sim à escassez de propostas concretas para assegurar o desenvolvimento sócio-econômico e a superação dos desequilíbrios internos e internacionais na distribuição da riqueza e dos meios para alcançá-la.

Se os resultados de Copenhague são inegavelmente positivos para os direitos humanos, o que se afigura preocupante foram as dificuldades para consegui-los.

Inconformados com os resultados das Conferências de Viena e do Cairo, especialmente com esta última, os governos que haviam registrado reservas e declarações interpretativas aos respectivos documentos finais, reabriram nas negociações de Copenhague todas as questões para eles duvidosas, como se os esforços de conciliação e acomodação daquelas conferências tivessem sido em vão, e como se os documentos delas emergentes fossem letra morta. Mais uma vez a Santa Sé e os países islâmicos procuraram fazer desaparecer os temas da saúde reprodutiva, dos meios de prevenção das doenças sexualmente transmissíveis, da família em suas diversas formas, da não-discriminação de gênero e da igualdade de direitos entre os sexos. Mais uma vez, ainda, os fundamentalistas religiosos, respaldados por governos ditatoriais e de países de tradição não-liberal, procuraram inserir nos textos em discussão linguagem que sobrepunha o relativismo ao universalismo dos direitos humanos, e que reinstaurava o conceito absolutista de soberania como escudo a práticas domésticas inaceitáveis no direito internacional.

De todas essas iniciativas, a última a ser contornada - graças à atuação do Brasil — simboliza de maneira eloqüente todas as demais.

Conforme tem sido prática em todas as conferências, as negociações de Copenhague deveriam ater-se a buscar o consenso sobre pontos já examinados nas sessões do Comitê Preparatório ainda indicados entre colchetes nos projetos em consideração. A não ser, naturalmente, que o conjunto de delegações entendesse unanimemente que algum assunto de importância essencial tivesse sido esquecido, por inadvertência, no processo preparatório - como foi o caso do compromisso sobre educação e saúde, proposto e negociado em Copenhague sob coordenação do Brasil, e consubstanciado no Sexto Compromisso da Declaração.

Quando as negociações já entravam na fase final, com poucos pontos pendentes nos grupos de trabalho, o Grupo dos 77 - criado na década de 60 pelos países em desenvolvimento para coordenar posições nas discussões sobre temas econômicos - aprovou, em momento de ausência do Brasil e da maioria dos demais países latino-americanos, como proposta comum, um novo parágrafo para o chapeau dos compromissos a serem assumidos em Copenhague, estabelecendo que "a formulação e a implementação de estratégias, políticas, programas e ações em favor do 
desenvolvimento social são de responsabilidade de cada país e devem levar em conta a diversidade econômica e social das respectivas condições, com pleno respeito aos diversos valores religiosos e éticos, contextos culturais e convicções filosóficas de seus povos". Redigida apenas nesses termos, a proposta representaria um óbvio retrocesso à universalidade dos direitos humanos, e uma revisão regressiva ao chapeau dos Princípios do Programa de Ação do Cairo - que reafirmava o respeito às soberanias e aos contextos e valores religiosos e culturais, mas "em conformidade com os direitos humanos internacionalmente reconhecidos". ${ }^{10}$

Um dos problemas que se vêm observando nas reuniões sobre temas sociais das Nações Unidas consiste, precisamente, na insistência do Grupo dos 77 em apresentar-se unido nos assuntos não-econômicos em discussão. Além de representar uma clara extrapolação dos objetivos originais de grupo, a coordenação de uma "frente" de países tão ampla e heterogênea em temas atinentes a direitos e conceitos éticos é praticamente impossível. Pior ainda, como os países de tradição liberal da América Latina raramente se interessam pelas discussões do grupo - com exceção do Brasil e poucos mais -, este tende a ser manipulado pelas delegações mais ativas de governos autoritários de diversos tipos, que têm, naturalmente, todo interesse em fazer passar suas posturas antiliberais como posições comuns dos países em desenvolvimento.

Ao tomar conhecimento do texto, a delegação do Brasil anunciou ao Grupo dos 77 sua discordância com a redação incompleta. Como, porém, ele já havia sido acordado previamente, comprometeu-se o Brasil a não tomar a iniciativa de objetá-lo nas discussões com os demais participantes da Cúpula, desde que estes o aceitassem tal como estava.

Nas discussões do grupo de trabalho pertinente, o texto foi objetado pela União Européia, tanto por sua extemporaneidade, quanto pela linguagem restritiva inaceitável. Após novo adiamento das discussões, a União Européia dispôs-se a relevar a extemporaneidade da proposta, desde que o texto passasse a incluir menção aos direitos humanos. Face às resistências ainda demonstradas pelos porta-vozes do Grupo dos 77, a delegação brasileira cumpriu o que anunciara: comunicou ao grupo de trabalho reunido sobre o assunto que, sem a menção imprescindível aos direitos humanos, o parágrafo não mais poderia ser encarado como proposta do Grupo dos 77, por não contar com seu apoio. Em função dessa intervenção, o chapeau dos compromissos de Copenhague passou a ler, em consonância com o texto do Cairo:

10 (10) Documento das Naçōes Unidas A/CONF.171/13, p. 12. 
"Nossa campanha mundial em prol do desenvolvimento social e as recomendações de medidas descritas no Programa de Ação são feitas com espírito de consenso e cooperação internacionais, de conformidade com os Propósitos e Princípios da Carta das Nações Unidas, reconhecendo que a formulação e a implementação das estratégias, políticas, programas e ações em favor do desenvolvimento social são de responsabilidade de cada país e devem levar em conta a diversidade econômica, ambiental e social das respectivas condições, com pleno respeito aos diversos valores religiosos e éticos, contextos culturais e conviç̧ões filosóficas de sua população, e em conformidade com todos os direitos humanos e liberdades fundamentais. Nesse sentido a cooperação internacional é essencial para a plena implementação dos programas e ações de desenvolvimento social". ${ }^{11}$

A Declaração e o Programa de Ação de Copenhague não chegaram, portanto, a reverter posições consensuais das Conferências de Viena e do Cairo em matéria de direitos humanos. Os riscos foram, porém, substanciais. E a reiteração de reservas a trechos dos documentos a eles atinentes indica que as resistências fundamentalistas continuarão por tempo indeterminado.

\section{PERSPECTIVAS}

É difícil imaginar, à luz das tendências concretas da história contemporânea, que a real situação dos direitos humanos no mundo possa corresponder aos propósitos e às recomendações das conferências das Nações Unidas. Estas têm podido manter, até agora, não sem dificuldades, o sentido de progresso racional que deve permear os esforços para a construção de uma realidade mais justa, nas esferas nacionais e internacional. Correm, porém, o risco de permanecer no nível do discurso face ao irracionalismo regressivo que vem caracterizando uma vertente importante da "pós-modernidade".

No dia 8 de março a sessão plenária da Cúpula Mundial para o Desenvolvimento Social foi inteiramente dedicada ao Dia Internacional da Mulher. As organizações não-governamentais de mulheres reunidas em Copenhague lançaram, então, uma campanha mundial, intitulada "180

11 Documento das Nações Unidas A/CONF.166/L.3/Add.1, p.10. 
dias para Beijing", destinada a mobilizar as consciências e as atenções para o período final da preparação para a IV Conferência Mundial da Mulher, em setembro. Enquanto isso, na Argélia, os fous de Dieu do FIS iniciavam, na mesma data, outra campanha, "em resposta" ao Dia Internacional da Mulher, incrementando a repressão a possíveis símbolos da liberação feminina, através do assassinato de mulheres de projeção pública no país - como a apresentadora de televisão Rachida Hammadi e sua irmã Houria Hammadi!2

Na presente confusão do Afeganistão, segundo a imprensa internacional, os jovens integristas taliban, que vêm conseguindo impor paz e ordem em partes do país, depois de haverem determinado clausura doméstica às mulheres das aldeias sob seu controle, optaram por permitir sua saída às compras, desde que não entrem nas lojas e vistam-se com indumentária que as oculte inteiramente. Em algumas regiões africanas, as mutilações genitais femininas, condenadas em todos os documentos internacionais, prosseguem com tal "naturalidade", que, no fórum de ONGs do Cairo, paralelo à Conferência sobre População e Desenvolvimento, o ginecologista sudanês Hassan Zecky, da Universidade de Khartoum, postulou a "necessidade de se diferenciar entre a má e a boa circuncisão feminina" (a segunda sem riscos para a saúde, nem choques psicológicos). ${ }^{13}$

No Ocidente, por sua vez, o cristianismo, em vários de seus ramos, reacende dogmas há muito não observados na prática dos fiéis. Campanhas de prevenção à AIDS com o uso de camisinhas são condenadas por líderes religiosos. A crise de valores e a falta de opções sociais produzem surtos de esoterismo. A religiosidade difusa se manifesta na proliferação de seitas messiânicas fundamentalistas, em que a teologia, o recolhimento da oração e a fé equilibrada dão lugar a rituais de fanatismo. Em meio à crise econômica praticamente universal, as fronteiras dos ricos se fecham aos imigrantes. Estes se tornam bodes expiatórios do desemprego e de todas as dificuldades domésticas. As "áreas cinzas" da miséria, dos excluídos, do crime e do narcotráfico, espalham-se. Em desafio ao poder do Estado, os "exércitos de mercenários" das máfias internas e do crime internacional se fazem cada dia mais presentes. A corrupção e a impunidade estimulam a criminalidade. $A$ insegurança induz à contratação de agentes particulares e à tentação da justiça pelas próprias mãos. A violência alimenta a violência e os direitos humanos passam a ser confundidos como "direitos de bandidos".

12 Segundo a imprensa argelina, entre os dias 8 e 20 de março, doze mulheres já haviam sido trucidadas, a começar por uma jovem arrancada da sala de aula e degolada.

13 Bryant, Elizabeth."Scholars and theologians condemn abuse of females". The Earth Times, 13 Set. 1994. 
A monstruosa explosão de um edifício público em Oklahoma City, em 19 de abril de 1995, trouxe à tona, de roldão, vários tipos de "fundamentalismos" a ameaçarem a vigência dos direitos humanos nestes tempos "pós-modernos". Em primeiro lugar, e acima de tudo, o do inaceitável recurso ao terrorismo para fazer valer qualquer causa. Em segundo, pela coincidência de datas com o aniversário do fim dramático do cerco governamental a David Koresh e seus seguidores numa fazenda de Wako, no Texas, em 1993, o das seitas milenaristas que ora proliferam em muitos países. Em terceiro lugar, o das organizações paramilitares de extrema direita, de cunho racista e puritano, amplamente conhecidas e disseminadas pelos Estados Unidos, que, de maneira semilegal, congregam e treinam milhares de cidadãos para ações contra o governo, "em defesa da Constituição e dos direitos humanos"14 — direitos estes por elas resumidos, de forma obsessiva, no direito à propriedade, e, mais grotescamente, no direito à propriedade de armas, estabelecido pela Segunda Emenda à Constituição. Em quarto lugar, o integrismo racista e xenofóbico das reações populares norte-americanas, chocadas com as evidências de que o atentado não tenha sido obra de estrangeiros, mas sim de cidadãos WASPs (White Anglo-Saxon Protestants). Por fim, o fundamentalismo liberal de Washington, ao recusar-se até hoje, com base na garantia da liberdade de expressão da Primeira Emenda à Constituição, a aceitar o Artigo 20 do Pacto Internacional de Direitos Civis e Políticos - que determina a proibição da propaganda de guerra e da advocacia do ódio racial, nacional ou religioso.

O episódio de Oklahoma é eloqüente demonstração, e resultado, do caráter nocivo de todos os fundamentalismos, inclusive os de inspiração liberal, incapazes de apreender e acomodar a natureza histórica dos direitos. O "direito de portar armas" da Segunda Emenda, não-fundamental e especificamente norte-americano, somente há pouco ligeiramente qualificado, remonta às lutas pela independência e apenas por elas se justifica. O direito à propriedade, entronizado na Declaração Universal de 1948, mas não consagrado no Pactos de 1966, é reconhecidamente passível de limitações, conforme previsto até mesmo por Locke. ${ }^{15}$ Quanto à liberdade de expressão -

14 Declaração de Ray Southwell, um dos líderes da Milícia de Michigan, Folha de S.Paulo, 22 abr. 1995.

15 "Labour being the unquestionable Property of the Labourer, no Man but he can have a right to what that is once joyned to, at least where there is enough and as good left in common for others". Esta e outras passagens do Second Treatise on Government são citadas por Jack Donnelly para demonstrar que o direito à propriedade não é tão ilimitado nos textos de Locke como se costuma dizer. Cf. Jack Donnelly, Universal Human Rights in Theory and Practice (Ithaca, Comell University Press, 1989), pp. 93-100. 
esta, sim, um direito humano inquestionável e universal - , seu uso não pode, de acordo com a ONU, servir para fins contrários aos demais direitos humanos. E é precisamente por isso que o Pacto Internacional de Direitos Civis e Políticos a contrabalança com as proibições do Artigo 20.

Em 1972 Umberto Eco já previa, ante as tendências então detectáveis no mundo, o advento de uma "nova Idade Média". Em suas palavras: "A vida política, entrando em crise, se subdividirá numa série de subsistemas autônomos e independentes do poder central, com milícias mercenárias e administração autônoma de justiça". ${ }^{16} \mathrm{O}$ "medievalismo" do mundo pós-Guerra Fria, sem sequer o amálgama de uma fé universal, é descrito em pormenores por Alain Minc, que o interpreta como "o rebaixamento da razão como princípio fundador, em proveito de ideologias primárias e de superstições desaparecidas por tanto tempo". ${ }^{17}$

A Idade Média antecedeu a noção de direitos humanos. Estes são uma conquista da Idade Moderna, mais precisamente do Iluminismo, hoje traduzida em obrigações jurídicas universais, e não podem ser apagados da História. Enquanto perdurarem os impulsos medievos da "pósmodernidade", tais direitos, mais do que as penalidades correspondentes a sua violação, tenderão a permanecer em sursis, na esfera internacional. Mas essa situação não pode ser aceita passivamente. Até porque o negativismo ferrenho da atualidade é essencialmente europeu e eurocêntrico.

Nem tudo tem sido negativo em todos os lugares nos tempos que vivemos. A América Latina, malgrado as múltiplas adversidades e alguns retrocessos isolados, é, sem dúvida, uma grande área geográfica, talvez a única, onde a democracia política se tem reafirmado no período pósGuerra Fria. Nem Chiapas, nem o crash mexicano, nem o "efeito tequila" abalaram as instituições democráticas do continente. A própria guerra Peru-Equador de 95, encerrada - ou, pelo menos, suspensa - de forma relativamente expedita, em negociações arbitradas por garantes das Américas, contrasta com os aparentemente intermináveis conflitos do Velho Mundo. Se este vem testemunhando uma desrazão da História, é importante que evitemos a contaminação em nosso hemisfério.

É significativo que hoje, ao contrário do que ocorria na década de 80, a Comissão dos Direitos Humanos das Nações Unidas mantenha tão poucos países latino-americanos sob monitoramento por relator especial ou perito designado dentro dos serviços de assessoria. ${ }^{18}$ Não quer isso di-

${ }^{16}$ Eco, Umberto. Viagem na irrealidade cotidiana. Tradução de Aurora Fornoni Bernardini e Homero Freitas de Andrade. Rio de Janeiro, Nova Fronteira, 1984, p. 76.

17 Minc, Alain. Le nouveau Moyen Âge. Paris, Gallimard, 1993, p. 10. Minha tradução.

18 Ver acima relação completa dos países atualmente monitorados. 
zer que a situação da região seja boa. Muito pelo contrário, os latinoamericanos, assim como o resto de mundo, sabemos das graves violações, de diversos tipos, que existem em nossos países. Estes, contudo, são agora os primeiros a reconhecê-las, abrindo suas portas ao diálogo e à cooperação internacional.

Em meio às múltiplas dificuldades que enfrentam, a Colômbia e o Peru não se têm negado a receber os relatores temáticos da Comissão. Se os Estados Unidos foram os primeiros a acolher missão do novo relator especial para as formas contemporâneas de racismo, o Brasil, em clara demonstração de boa fé, já autorizou a visita solicitada para $o$ ano em curso. E o governo brasileiro acaba de dar outros bons exemplos de sua determinação na matéria, ao divulgar amplamente seu primeiro relatório ao Pacto Internacional de Direitos Civis e Políticos, em fevereiro de 1995 e ao receber, em março/abril, com absoluta liberdade, o Secretário Geral da Anistia Internacional.

Se em partes do Velho Mundo os direitos humanos se encontram em sursis, esse não deve ser - e não é - o caso das democracias das Américas. As dificuldades latino-americanas são muitas e as violações, em todo o hemisfério, muito sérias. Mas os governos não querem compactuar com a regressão da História, como demonstra a ênfase dos compromissos sobre direitos humanos assumidos pelos Chefes de Estado e de Governo na Cúpula de Miami, em dezembro de 1995.

$\mathrm{Na}$ década de 50, Wright Mills sentia que os fundamentos da modernidade - razão e liberdade - não pareciam manter nexos intrínsecos de reciprocidade. Temia ele, então, que o aumento da racionalidade pudesse não produzir aumento de liberdade. ${ }^{19}$ Diante do que se tem visto nesta "pós-modernidade", o temor mais plausível hoje parece ter os termos invertidos: de que o aumento da liberdade aniquile a razão. $E$ de que a liberdade conquistada se torne "liberticida".

Se a Razão kantiana encontra-se em fase de suspensão no processo histórico, que pelo menos, como deseja Celso Lafer, a complementaridade de interesses possa servir à prevalência de um universo grociano solidário pela interdependência. ${ }^{20}$

A alternativa da lei da selva e das soberanias hobbesianas, longe de garantir esperanças de paz e progresso a qualquer comunidade, nacio-

19 Wright Mills, C. The sociological imagination. Citado por Barry Smart, Postmodernity (Londres, Routledge, 1993) p. 26.

20 Lafer, Celso. Soberania e subordinação - reflexōes sobre a ética dos direitòs humanos no plano internacional, exposição no Painel "Ética nas Relações Internacionais", XV Conferência Nacional da OAB, 1994. (Este texto é publicado neste número de Lua Nova com o título "A soberania e os direitos humanos".) 
nal ou internacional, oferece perspectivas funestas ao novo milênio que se avizinha.

JOSÉ AUGUSTO LINDGREN ALVES é diplomata, membro da Subcomissão de Prevenção da Discriminação e Proteção das Minorias da ONU, e foi delegado à Cúpula Mundial para o Desenvolvimento Social. Na mesma área temática publicou em Lua Nova (n. 32, 1994) "Direitos humanos: o significado político da Conferência de Viena". 


\title{
1995: DIREITOS HUMANOS EM "SURSIS"
}

\section{JOSÉ AUGUSTO LINDGREN ALVES}

\begin{abstract}
Apesar de a Conferência de Viena de 1993 ter reafirmado por consenso a universalidade dos direitos humanos e a legitimidade da preocupação internacional com eles, alguns Estados recomeçaram a prática de rotulá-los de "ocidentais" e de recorrer à concepção tradicional de soberania para evitar a monitoração de sua situação interna. $O$ ressurgimento dessas atitudes dentro da Comissão das Nações Unidas sobre Direitos Humanos, juntamente com a resistência mostrada por esses mesmos governos, em associação com outros, para aceitar na Cúpula de Copenhague sobre Desenvolvimento Social os avanços consagrados nos documentos aprovados pela Conferência do Cairo sobre População e Desenvolvimento, sinalizam dificuldades à frente para os esforços internacionais de proteção aos direitos humanos.
\end{abstract}

\section{5: HUMAN RIGHTS "IN SUSPENSION"}

Although the Vienna Conference of 1993 reaffirmed by consensus the universality of human rights and the legitimacy of international concern for them, some States have reinitiated the practice of labelling them as "Western", and of resorting to the traditional concept of sovereignty to avoid the monitoring of their internal situation. The revival of such attitudes within the UN Commission on Human Rights, together with the resistance shown by these same governments in association with others to accept at the Copenhagen Summit on Social Development conceptual advances already enshrined in the documents adopted at the 
Cairo Conference on Population and Development point to serious difficulties ahead in the international efforts to protect human rights. 